\title{
Automation Approaches to Book Licensing
}

\author{
Business Studies and Information Science Aspects \\ of a Phenomenon from Literary Life
}

\section{Introduction}

When discussing the licensing of books, the focus is typically on fictional content, or more specifically, on the migration of literary fiction across linguistic boundaries. From the point of view of the scholarly disciplines primarily involved - literary studies and comparative literature, among others - this focus does make sense. Licensing, however, moves past the realm of fiction. But apart from the fact that there is, of course, also the licensing of non-fiction materials, the licensing of content can also happen across various formats (for example, from hardcover to paperback) and between types of media (for example, from book to film), which shifts its relevance beyond the context of content. Licensing can be seen as part of a cultural practice that reaches beyond simply writing or authoring texts, namely publishing. This is where, in the differentiation of disciplines, book and publishing studies comes in. Book and publishing studies covers the materiality and mediality of book communication, from the production and distribution to the reception of books - books, of course including digital manifestations of books like e-books, book apps, or PDFs of scholarly texts.

The subject of this article is not book licensing in its entirety, which would also have to include e.g. a historical perspective; rather, I will specifically discuss issues of the automation of the licensing process. Automation approaches develop in an environment where, in a globalized world, there is additional demand for licensing, as well as additional supply with respect to technological solutions for licensing tasks, usually in the form of digital and artificial intelligence options. Systematically, the latter aspect is covered by information science, information studies, and business informatics.

The focus chosen, however, challenges the traditional and core methodological "toolset" of book and publishing studies: it can be assumed that the dominating hermeneutics approaches of book and publishing studies might not suffice when trying to make sense of licensing automation, as hermeneutics

Christoph Bläsi, Johannes Gutenberg-Universität Mainz

Ә Open Access. () 2021 Christoph Bläsi, published by De Gruyter. (c) BY-NC-ND This work is licensed under a Creative Commons Attribution-NonCommercial-NoDerivatives 4.0 International License.

https://doi.org/10.1515/9783110713015-024 
can do little here beyond describing the process and its results and potentially analysing and interpreting the perception of the agents and bodies involved. Hence, focusing on the subject of book license automation and the business that surrounds it naturally also gives rise to issues concerning the discipline of book and publishing studies itself, e.g. the self-perception and the theoretical and methodological foundations of the discipline.

\section{Book and Publishing Studies; the (Scholarly) Context of the Discussion}

\section{The Book World and Book and Publishing Studies - an Integrative View as Vanishing Point}

The primarily philological thrust of this volume suggests that a few words should be said about the discipline this contribution is rooted in, its position within the concert of relevant disciplines, and its theoretical and methodological coordinates. To put it very simply, book studies as it is represented at a number of German universities is the combination of the history of books on the one hand and publishing studies on the other. Publishing studies, the study of contemporary publishing, does exist as a separate discipline in various other countries, particularly in the UK.

Historically, being a "spin-off” from German literary studies, book studies ${ }^{1}$ is more or less restricted to the hermeneutics "toolset" it inherited (this restriction is not as distinct in publishing studies of e.g. anglo-saxon shaping). This methodological heritage appears to be somewhat strained in the face of many phenomena moulding the current book economy and culture, particularly when it comes to issues of its digitisation (cf. Bläsi 2015). This shortcoming is brought home when looking at other disciplines that cover aspects of the current book world. Business studies, communication studies, business informatics, and information studies all have a broader, or at least significantly different, methodological "toolsets" at their disposal. Methods of empirical social research or constructivist approaches (analogous with those of engineering sciences) could be mentioned. Scholars from these disciplines, using the methods of their disciplines, are able

1 In this article, I will talk about the part of book studies that is concerned with the contemporary book world, as well as about publishing studies proper and refer to them together as "book and publishing studies" or in places "book studies" for short. 
to participate in the discourse about the digitised book world with numerous and valuable contributions, indeed.

Particularly since book studies is only represented in a small number of institutes and study programmes in Germany, holistically integrating a superset of appropriate theories and methods from other disciplines is not a viable option. Other options, therefore, have to be considered. One option is to see the main role of book studies as one of integrating different perspectives (including its own hermeneutical one) onto the media and communication system of books, crossing boundaries between disciplines, theories, and methods. However, even choosing this option means that the methodological expertise of book studies has to be extended, since an integration of different perspectives presupposes a solid understanding of the theories, methods, potentials, and limitations of the disciplines these perspectives are rooted in.

For the issue in focus here, the automation of (book) licensing, and taking the disciplinary landscape of the year 2020 as a point of departure, business studies and, among others, information science and information studies, provide the concepts, theories, and methods for an appropriate analysis. These methodological-theoretical "imports" provide levers to address strategic management issues regarding automation on the demand side (imports from business studies), and artificial intelligence issues regarding automation on the supply side (imports from information science and information studies), respectively.

\section{Previous Work on Licensing}

Licensing issues in the book industry are covered predominantly from a legal and operational perspective, as well as, of course, from a statistical one. With regards to the language and national literatures focused on in this publication, it is known, for example, that in 2017 the book export to Spain amounted to $37,5 \mathrm{~m} €$ (Börsenverein des deutschen Buchhandels 2019: 80) and that in 2018, 151 translations from Spanish (1.5\% of all translated titles) appeared on the German market (Börsenverein des deutschen Buchhandels 2019: 98), whereas 373 licenses were sold to Spain (4.8 \% of all licenses sold) (Börsenverein des deutschen Buchhandels 2019: 107-108).

Beyond this type of analysis and the occasional coverage in $\mathrm{b} 2 \mathrm{~b}$ magazines of the book trade, there are two main consolidating accounts about the business of book licensing, both with a primarily practical-vocational focus. They are Lynette Owen's Selling Rights (Owen 2015) and Petra Christine Hardt's Buying, Protecting and Selling Rights. Wie man urheberrechtlich geschützte Texte 
erwirbt, sichert und verbreitet (Hardt 2014). Lynette Owen worked for Pearson for many years, and Petra Christine Hardt works for Suhrkamp.

Although these books have to be categorised as how-to books rather than as theoretical accounts, there is good reason not to underestimate their relevance and significance also within a scholarly context. They can, in addition to what had been said concerning the theoretical and methodological "toolset" of book studies above, be seen as initial critical reflections of an essential and complex cultural practice, namely "book making”, or publishing. Such a view is clearly compatible with John Maxwell's alternative (integrative) conception of publishing studies (that is how they label it in Vancouver) which sees it explicitly as exactly that: as a 'higher order' cultural practice that is (exercised in a mindset of experimentation and) continuously subjected to critical reflection, in the first instance in a manner that is agnostic to boundaries between disciplines (cf. Maxwell 2014).

\section{Artificial Intelligence in Publishing - an Example Instead of a Holistic Account}

The concepts from business studies I will make use of will be introduced below. With respect to technology, automation does not necessarily require the use of artificial intelligence (AI). However, AI applications in publishing have increasingly been discussed (cf. Bläsi 2019) and open up an extensive arena full of new options for automation. When talking about the use of artificial intelligence in publishing, typically editorial processes are focused on. This is the reason why - despite there also being AI applications for e.g. dynamic pricing or asset management - one application, QualiFiction's LiSA, is currently talked about in Germany in particular. This application is advertised as a tool for supporting editors in evaluating manuscripts, by, for example, categorizing them into genres or, going farther, by predicting the size of their potential readership. It serves well as a catalyst to guide the discourse about potentials, limitations, and risks of applying AI to publishing. This discourse requires, however, concepts and argumentations that go beyond what would be possible by just using hermeneutics and only looking at LiSA and its use "from the outside". Without going into detail here, LiSA combines modules from all three main approaches to contemporary artificial intelligence: rule-based, statistical, as well as solutions that utilise the deep learning paradigm (cf. Bläsi 2019: 173-174). The last item in the list, deep learning, a further development based on neural networks, has been broadly discussed lately and has contributed to most of the visible advances in artificial intelligence in recent years. The implications of these different approaches and in particular the possible consequences of the 
use of tools based on them for publishing, publishing houses, and society have to be assessed. Following this, fundamental decisions between the extremes of foregoing cogitation about the implications altogether on the one and taking a broad and long-term perspective as well as taking responsibility for the digital transformation of culture and society on the other hand have to be made by publishing houses. It is apparent that humanities-related issues are clearly touched upon here, but that insights from business informatics or information science are undoubtedly needed as well.

After a few methodological remarks concerning book (and publishing) studies, a short account of the previous coverage of book licensing matters, and the reference to a somewhat exemplary $\mathrm{AI}$ application in publishing, we come back to an interventional version of the core question of this contribution, namely, in how far recent technological developments can help to increase the - politically and culturally desirable - flow of (licensed, typically translated) written content across linguistic and cultural spaces. In order to be able to tackle this question the main characteristics of traditional licensing must first be outlined.

\section{Traditional Licensing and its Analysis}

\section{Traditional Licensing and its Limitations}

The traditional trading of title licenses in the publishing industry is a complex business. ${ }^{2}$ It requires a considerable amount of experience and knowledge since it cannot be handled schematically or according to fixed rules, and it is often largely based on personal relationships (cf. Hardt 2014, Owen 2015). Jane Tappuni dwells on a number of typical complications in more detail by pointing out that "[. . .] rights ownership is inherently complicated. IP for a work might sit in several places due to format and ownership. The work might have multiple licenses, but the tracking of the work doesn't sit in one place. It is disparate, making it very hard for the licensor to get a global picture of their rights distribution" (Tappuni 2018). This sketchy analysis clearly shows determinants that appear to make efforts to automate the process as a whole, or even decisive parts

2 Parts of the sections "The Traditional License Business and its Analysis" as well as "Approaches to an Automated License Business" I have also used in: Christoph Bläsi: "BuchLizenzgeschäfte mit einer alternativen Marktstimulierungsstrategie und die Notwendigkeit der Automatisierung" (to appear in a volume edited by Maud Pfaff). I have explicitly been granted the permission to do so. 
of it, presently difficult or outright impossible. It can furthermore be assumed that, due to the fact that the negotiation and further processing of licenses is complex and therefore expensive, quite a few licensing business opportunities are not even considered more closely. After all, the proceeds expected from a licensing deal should typically be greater than the efforts involved on both ends. Examples of licensing deals that are generally "left behind" are ones that involve small quantities of content, such as shorter texts like poems or short stories, or texts written in languages with small (target) markets. The question now is whether or not traditional licensing, which I will describe as a "short head" business that follows a differentiation strategy (using categories from strategic management and from retail and web economics, discussed in more depth below) can be complemented by a business model following "long tail" and cost leadership strategies. This would enable the realisation of business opportunities that had previously been missed.

\section{Analysis Approaches from Strategic Management and Retail/Web Economics}

To systematically postulate and describe a licensing business that goes beyond the traditional one, categories are necessary or at least helpful that move beyond what book and publishing studies has at its disposal, given its traditional methodological and theoretical orientation as a humanities-based discipline. These categories come from business studies, or more specifically, from strategic management and retail and web economics.

According to strategic management (cf. Barney/Hesterly 2012) and not surprisingly, the strategic process of a company begins with an analysis of the current situation. This analysis can be divided into an analysis of the company's surrounding world, as well as an analysis of its "inside world". A frequently used analysis tool for the "outside world", or the market side, is Michael Porter's 5Forces Model (cf. Barney/Hesterly 2012: 53-65). This model assumes that the chances for a company to gain a competitive advantage over others in a particular market is, among other things, dependent on the competitive pressure, the bargaining power of suppliers, and the danger of (categorially) new market entrants. Concepts that play a role in the analysis of the "inside world" are assets and competencies, both concepts of the resource-based view of management (cf. Barney/Hesterly 2012: 84-101). Assets constitute what a company possesses tangible and intangible items such as a brand name, a branch networks or a customer database - while competencies are the company's ability to combine its assets into marketable products and services. Such products and services, for 
example, addressing customers from a customer database (asset), with explicit reference to the brand name (asset) in a direct marketing campaign (combination of assets = competence), are designed to provide the company with a competitive advantage. The rarer and the more inimitable a company's assets and competencies are, the better. This insight comes from the so-called VRIO framework, which Barney and Hesterly use to describe assets and competencies; this framework focuses on the value, rarity, imitability and organisation of assets and competencies.

Strategies can systematically help companies gain a competitive advantage, but only if they assume the baseline situation as assessed by the different steps of analysis (as previously discussed) as their point of departure. By way of abstracting from concrete cases, business studies research was able to organize baseline situations from different companies in different times into a number of categories. Mapped onto these categories, promising fundamental strategic options have been identified. These fundamental strategic options are often arranged in pairs of opposites. One central pair of opposites of strategic options is the one with a (product) differentiation strategy (cf. Barney/Hesterly 2012: 148-176) on the one hand and a cost leadership strategy (cf. Barney/Hesterly 2012: 120-145) on the other. Using a differentiation strategy, a company attempts to make an offer to customers in the form of products (or services), that satisfy their needs as precisely as possible. The development and production of such products tends to be more complex and more expensive, but the model assumes that customers are ready to accept a correspondingly higher price. The proceeds derived from this price premium then compensates for the higher costs incurred on the side of the company. In contrast, when using a cost leadership strategy a company seeks to produce products as cheaply as possible, passes this advantage on to customers in the form of low prices, and thereby achieves the high sales figures required to cover fixed costs. To present examples for each of these two basic strategies - and this goes beyond Barney and Hesterly's Strategic Management and Competitive Advantage: Concepts and Cases - I will have a look at the automotive industry. Audi is clearly pursuing a differentiation strategy (differentiated product, price premium), while the Romanian budget carmaker Dacia is pursuing a cost leadership strategy (cheap production, high volume). Whether it is possible to combine these two strategies is an ongoing academic debate, as it seems like that would constitute an ideal model incorporating the best of both worlds: a precise satisfaction of consumer needs and, at the same time, low costs and a high sales volume. Recently, it has been argued that this might in fact be possible under certain circumstances (cf. Barney/ Hesterly 2012: 172-175), namely with the help of digitised development and production processes under the headings like mass customisation or Industry 4.0. To take another example from the automotive industry, the Fiat Cinquecento is both 
relatively inexpensive and, at the same time, individualisable to a high degree. For a considerable amount of time, Fiat claimed that no two cars among the hundreds of thousands had come off the assembly line were exactly identical due to all the various individualisation options. This indicates that the Cinquecento can be seen as a differentiated product that is also produced relatively cheaply.

The term "long tail" and its much less frequently used opposite "short head" come from retail and web economics (cf. Anderson 2007). "Long tail" refers to the phenomenon and intentional strategy of selling a large number of unique items with relatively small quantities sold of each, in contrast to selling large quantities of a small number of products, which is referred to as "short head”. In The Long Tail - Der lange Schwanz, Chris Anderson (Anderson 2007) has identified the long tail pattern as an essential feature of online e-commerce. The term has since become an integral part of the analysis inventory for the web economy. A pithy concretisation of the concept of the long tail comes in the form of an often-quoted statement by an unnamed Amazon employee: "We sold more books today that didn't sell at all yesterday than we sold today of all the books that did sell yesterday" (Reason Street 2014). This employee, speaking about his or her company, has become something like an industry myth and this particular quote has been circulated in various wordings. Of course, due to low quantities, a long tail strategy can only be made work economically if original costs are correspondingly low. This links, in this case, the long tail strategy to the cost leadership strategy as introduced above.

\section{Traditional Licensing - the Analysis}

Applying these concepts to traditional licensing, it is easy to see that this can be analysed as a business following a differentiation strategy. As has previously been explained, the licensing business typically requires detailed knowledge about the target market on the side of the licensor, mostly ensured by personal relationships that often had been developed over the course of years. The publisher, offering content to be licensed, tries to present and market its content in an individualised manner, possibly even having developed the content with a possible licensing agreement and specific licensees in mind. This suggests that in order to make sure that the content to be licensed is likely to satisfy sustained or current customer needs as precisely as possible, the publisher typically does not shy away from costs (to be imposed on the license fee to be paid, ultimately). Customer needs to be taken into account are the ones of the license buyer, but in a mediated fashion also the ones of book buyers and readers in the target market. Due to the considerable efforts required, it is realistically 
only possible to apply this process to a rather small selection of the licensor's portfolio, as well as only for a few selected, particularly relevant language markets. These are both dimensions of a short head strategy: a small number of products and deals on - comparatively - large scales. The traditional licensing business can, therefore, be described as a business that follows a short head differentiation strategy.

Usually a licensing enquiry directed to the licensing department of a publishing house on an individual basis will be dealt with in a benevolent manner, even if this enquiry comes from a small language market or only concerns a minor text. It might even lead to an agreement, regardless of whether or not the proceeds from this transaction could potentially cover the costs incurred for closing the contract and transferring the content, or possibly even provide a contribution margin for the underlying intellectual property. However, such a business practice, as pleasant as it may be on an individual level, is not scalable, in the sense of not being applicable to a large number of cases. In accounting terms, such cases would be dealt with as being on the receiving end of what is called a "mixed calculation", which is a widespread business practice in other areas of the book industry as well ${ }^{3}$. Therefore, it does not make sense for publishers to make such small business possibilities explicitly public by way of, for example, license marketing, thereby inviting additional interest. Proactive marketing of the licensing of small quantities of content and of licensing in small language markets only makes sense if the costs for these types of deals (marketing, closing the contract, content delivery) can be reduced to an extent that the small projected proceeds become economically interesting. If it is assumed that there is, in fact, a market for small quantities of content and small language markets, then the question is this: what are the prerequisites for a long tail cost leadership licensing business, and how can the costs for marketing, closing the contract, and content delivery be reduced significantly and systematically?

3 Following a mixed calculation, an offsetting between profitable and less profitable products takes place: low margins of one product are compensated by correspondingly higher margins of another product. 


\section{Approaches to an Automated Licensing Business}

\section{How Costs for Marketing, Closing a Contract, and Content Delivery in Licensing can be Reduced}

Since the acquisition of in-depth knowledge about target markets and personal commitment vis-à-vis license customers have been recognised as main drivers of the costs for licensing transactions on the supplier's side, this is where cost reductions have to start. If the number of target markets is large but superficial knowledge of the respective target markets seems to be sufficient, there is an obvious way to proceed. Taking the long tail side of its portfolio, the licensor might try to rely on the proactive interest of potential licensees. In order for this to work, the licensor has to present its offer(s) in an easily accessible place for all prospective licensees to access. The offer(s) must be presented in an explicit and well-structured way so that prospective licensees get all relevant information needed to make licensing decisions, ideally without further enquiries. This place can, of course, only be the web. In order for interested publishing house to reduce search efforts, and hence costs, as well as to possibly give its own offer(s) a competitive advantage, the licensor should be familiar with known triggers for selecting an offer over others. The decision to take content presented on the web into closer consideration and to check the information given in greater detail (for example by inspecting the texts to be licensed or reading samples from them, in case they are made accessible on the web platform) might be dependent on expectations based on certain features of the content itself, or on its metadata and paratexts. Such expectations might, for example, be based on previous experiences and business relationships with the licensor, or on accessible third-party evaluations; on the web, such evaluations cross borders easily. Brands as used in the publishing industry, authors, characters, series, or, of course, publishing imprints, support the former, whereas a literary prize or bestseller status would be examples of the latter. Obviously, as a licensor it is advisable to make explicit use of such assets by harnessing brands and linking to third-party evaluations. Irrespective of the remaining challenge to get prospective licensees interested on a global scale in the first place, following advice like the one just given might indeed limit the amount of enquiries from the side of potential licensees and hence considerably release burden from employees of the licensor, at least in so far as such enquiries are triggered by just the lack of information. It is not so easy, however, to identify spots for cost reduction further on in the process, as usually steps are entailed that go considerably beyond the explication of standardised information. It is precisely these steps that could have, so far, only been exercised in the form of actual 
personal encounters. If it is assumed that, due to the necessity of in-depth knowledge about the content and its potential market, as well as due to the need to convey a consistent image of the brand (specifically corporate behaviour using, for example, consistent wording and a specific communicative style), finding cheaper alternatives in the form of offshoring these interactive steps to a call centre in a country with lower wages is not an option. Therefore, significant cost reductions for the steps beyond the explication of (marketing) information will only be possible by way of automation.

In the following, I will present products and services as well as explorative approaches, which, by way of utilising different degrees of automation, could help to make (book) licensing simpler, and hence more economical in the near future. Of course, companies and projects offering such products and services do not appear on the marketplace with the message that they want to support long tail differentiation strategies in the licensing business as the issue has been framed in this article. A marketing statement from IPR License, a provider of such solutions, rather sounds like this: "Permissions licensing is a perfect area for automation. If the permissions process is not automated this requires the publisher to check the rights, come up with a price and email the permissions seekers back. This is time consuming, often taking months, and is hugely inefficient” (IPR License 2017).

\section{Exemplarily: the Products of IPR License}

IPR License is an international digital licensing marketplace for the publishing industry, founded in 2012 and now essentially controlled by Frankfurt Book Fair. ${ }^{4}$ Other shareholders are the Copyright Clearance Centre and the China South Publishing \& Media Group. IPR License is a self-proclaimed digital marketplace where providers of licenses and potential customers meet. This marketplace is meant to complement the opportunities offered by existing marketplaces for licenses, above all by book fairs like the ones in Frankfurt and London. Its contributions feature the presentation of license offers that first of all induce or increase their visibility. As is typical for so-called two-sided platforms, however, offers are

\footnotetext{
4 It is not the intention of this article to give a comparative, let alone exhaustive overview of different providers of automation solutions for the licensing business. I have chosen the offers by IPR License as the main examples because they are prototypical and because they have a prominent market position. Moreover, IPR License is economically linked to Frankfurt Book Fair, the most important license trading location in the (real) world. The analysis does not include a judgement about the quality of the products and services offered.
} 
not only just presented, but actual transactions are also made possible. For this, such platforms require digital backend solutions designed for their specific purposes. Therefore, IPR License can offer some of the various digital tools it has developed to support the licensing process on its platform also in other product formats, to publishers directly. According to the information given on their website, offers so far (as of March 2019) have been inspected by potential rights buyers from more than 214 countries and 267 linguistic areas. As has been pointed out, the services offered address not only efficiency gains in interpublisher relations, but also the management of licenses within publishing houses. The main digital products of IPR License are marketed under the names "Instant Rights” and “Instant Permissions”.

IPR Licence's Instant Rights is a product that allows publishers to present and market content to be licensed to registered users. These users can view content and, after and in case they have chosen an offer and paid for it, download it for further use right away, under the conditions of the license just acquired. When looking at this process from the point of view of effort and workflow, it is important to note that it is carried out without the involvement of employees on the provider's side. As an alternative to having low-involvement offers presented and marketed on IPR License's website, the necessary software functions can be integrated into the publisher's website. The inviting advertisement on IPR License's website, "Let Instant Rights automatically handle low-value transactions, leaving you to focus on high-value deals” (IPR License), strongly points towards essential aspects of the above mentioned retail / web economics dichotomy, long tail and short head ${ }^{5}$. Instant Rights tries to limit or save human intervention for a certain type of licensing transaction on the side of the provider - if so desired only up to the step it might not want to be automated, though, the final approval of a transaction. Instant Rights can do all of this, as far as can be seen from the surface, without overstepping the boundaries between effective 'smart' software and artificial intelligence proper. This distinguishes it from some of the applications presented in the following.

As a product, IPR License's Instant Permission, the second of IPR's main products, is not quite as relevant in the given context; looking at it, a few relevant aspects can be illustrated, though. Instant Permissions largely implements the traditional licensing process as described above - a process which, due to its complexity, cannot reasonably be fully automated any time soon. Instant Permissions offers publishers digital support for process management, mainly with respect to associated administrative tasks of the process. This includes, for

5 For more on that, see Miller (2019). 
example, documentation and accounting issues, as well as the provision of interfaces to other ICT systems and indeed to customers ${ }^{6}$. Depending on the provider's demands, existing ICT landscape, and technical capabilities, web forms can e.g. be presented to potential licensees on behalf of the publisher. Whatever gets entered into such webforms by potential licensees triggers human processes in the licensing department of the licensor. This is a typical example for computer-supported process management. The applications can be individualised to a high degree and adapted to the specific needs of the publishing house so that, for example, the web forms not only appear in its corporate design, but also implement its specific business rules. In particular, this allows publishing houses to specify when exactly the automated process ends and the enquiry is presented to decision makers in relevant departments. The management of rights in a publishing house in toto, usually incorporating a dedicated rights management system in its centre, goes beyond negotiating and concluding license agreements as is the focus of this article. The corresponding functional extension is, however, also offered by IPR License, for cases in which this component of the digitisation of publishing processes has not yet been realised in the publishing house earlier.

\section{Beyond Pre-Fixed Conditions and the Automation of the Transaction: Ideas for the Future}

Following this short digression into the computerised support for the management of traditional licensing processes, we are now back to the main argument concerning the automation of licensing processes following a long tail and cost leadership strategy. The product Instant Rights of IPR License as presented above has already shown that it is possible to implement systems that realise at least some of the corresponding requirements in a relatively simple, but quite effective manner, without the use of artificial intelligence proper. However, it is still easy to identify cases for which types of automated systems like Instant Rights cannot yet decrease the workload for employees - such systems can for example only operate under the condition of pre-fixed prices and conditions. Moreover, important process steps (for example, verifying the receipt of payment) have to be fulfilled separately and inevitably require the involvement of people. It would certainly be way too optimistic to assume that a central (international) body that manages rights and the transaction of those rights, also

6 All these software components are realised as software-as-a-service (SaaS) solutions that run on IPR License's servers rather than on the ones of the purchaser. 
capable of taking stock of the status of account payments, could be operational any time soon. Therefore, essential parts of the automation process need to be decentralised.

A decentralised architecture is one of the underlying principles of blockchain technology. Jane Tappuni makes a proposal in this vein, following her analysis that the licensing process was "broken”. “[. . .] Building a (decentralised, C.B.) global rights database using blockchain technology is, in my view, the obvious solution" (Tappuni 2018). Jane Tappuni combines this with a short introduction of the blockchain concept, which begins with the factual impossibility of building a central super-database that combines all the relevant license master data with transaction data from participating publishers' company-internal systems. "Here is a simple, one line definition of blockchain: it is a way of decentralising transactions, taking them out of our corporate systems and making them open and accessible to all” (Tappuni 2018). In an extended license business automation agenda, as it were, the step prior to the payment using blockchain technology just addressed - negotiating, reconciling different interests with regard to conditions like price - definitely looks like a task for professional and experienced buyers and sellers which seems particularly hard to automate. However, since involving experts is excluded in the scenario chosen because of the low business volume to be expected (and allowing only predetermined prices and conditions is not an option), the only way forward is to implement at least basic automated negotiation capabilities. These negotiation capabilities should cover price, duration, and geographical area of the license, at the very minimum. Going further, they could for example also cover a specification of the forms of media that the agreement is supposed to extend over - and indicate potential "red lines" for every dimension of the automated negotiation. This would undoubtedly require the use of artificial intelligence proper. In such a case, it makes sense to automate operations on the side of both the potential licensor and licensee, as otherwise the licensee might incur costs that are disproportionate to the potentially small volume of the business under negotiation.

The next step beyond products like IPR License's Instant Rights would, therefore, be an intelligent software agent acting for the licensor, who would offer itself as a partner to the (intelligent software) agent of potential licensees. Pairs of such agents would enter into a "conversation" and start negotiations about content searched for on the one and content offered on the other side. The full picture of such a process would include the person responsible on the licensee's (!) side compiling metadata of the content he or she is looking for and the key parameters surrounding an intended "deal", namely duration, regions covered, media forms covered, and price. A relative prioritisation of target parameters and "red lines" concerning dimensions of the agreement or combinations of 
different dimensions might also be included. Then the software agent, equipped with these orientation data, would try to identify suitable content on the web offered for licensing. This can be achieved via comparing the metadata of offered content with the metadata of content looked for, starting with imperative highlevel variables like genre. It is also conceivable to make use of considerably extended metadata at this point, for example in the form of semantic web triples on both the supplier and demand sides. Such metadata could be much more granular and require or indicate, respectively, for example, whether or not the protagonist is or should be female and/or young. Alternatively, reading examples of the offered texts could be compared to texts specified in advance by the potential licensee (to help to specify the texts looked for) according to their similarity; algorithms that analyse the similarity between texts are typical and well-developed artificial intelligence/digital humanities applications.

If the two software agents involved in this "conversation" agree ${ }^{7}$ that there is serious interest in concluding the transaction, an attempt must be made to equalise the conditions offered by the licensor (with its software agent) and the ones conceivable to the potential licensee (with its software agent). It is exactly at this point in the process where the abilities only found in systems with artificial intelligence become indispensable. Essentially, these intelligent systems must be able to execute specific strategies on the basis of "mindsets" on the side of the licensor and the licensee, respectively. These "mindsets" result in "negotiation styles": cautious, dashing, with or without alternative business opportunities in the background, etc. If an agreement is reached, the transaction will be documented in a blockchain, thus making it impossible to manipulate the result afterwards and, in effect, legally binding; for the licensor, this constitutes an enforceable claim to a payment from the licensee. I will not present this in greater detail here, because it is a topic in its own right, the subtleties of which do not contribute to the understanding of the main argument. In this process step, payments can be automatically distributed also to other beneficiaries, for example upstream (author or authors). Finally, the content delivery can be completed, for example in the form of an enabled download.

In the case that the two parties do not reach an agreement - this can be due to "red lines" being touched in the negotiations, for example by disagreeing over price, duration, or location - contingency conditions can be specified. The licensor would, in this case, need to consider it worthwhile to involve a person with decision-making authority. This person could then, in further person-to-person

7 The attribution of intentionality to machines here is only a manner of speaking, not the result of a corresponding analysis. 
negotiations, also deliberately violate original negotiation objectives, overrule "red lines" that had bound the software agent initially - in the wider or more long-term interests of the company.

\section{Conclusion}

It is clear that a certain degree of automation in book licensing is already here, and that there is likely more to come. Attempts and plans to automate book licensing must not be seen simply as a cost-cutting technique. With the help of concepts from strategic management and web/retail economics, they could also be analysed as a way for publishers to implement consciously chosen strategies and making those strategies economically viable. It allows publishers to have a competitive advantage by following up business opportunities that would have been considered too small previously. This effectively allows more content to get licensed - content that had previously not been taken into consideration by publishing houses due to the unfavorable relationship between effort expended and returns expected. With an international focus, this increases the diversity of content available cross-culturally; this is a result that can only be advocated for. Licensing automation, when looked at it this way, is a contribution to the vitality of the intellectual property business.

Automation attempts in licensing will, as we have seen, not stop at simple products like Instant Rights by IPR License. Future attempts might not leave traditional knowledge- and relationship-intensive licensing practices completely unchanged, either. However, the fact that licensing has been dependent on strong knowledge of content and markets and on personal relationships for its success, it is unlikely to be taken over by machines in the foreseeable future.

Why is all this interesting in a literary studies context? In traditional licensing, the people involved were typically included in the literary studies discourse, at the very least by way of a literary studies education. When some of the business, starting with long tail cost leadership cases, gets taken over by machines, the question arises, how insights and values of literary studies can find their way into such systems. How can its voice be heard by those who develop the algorithms? The discipline that provides the bridge over this gap might well be computational philology, a discipline of digital humanities.

With respect to book/publishing studies as a discipline, it has been made clear that concepts from beyond its traditional "toolbox" have made it possible, at least much easier to substantiate and analyse what is going on in book licensing and book licensing automation. More detailed insight into the potential 
applications of artificial intelligence (not taking into account its limitations and risks, though), combined with concepts from business studies have helped to contextualise book licensing and its automation in a fruitful manner. Similarly interesting is the finding that, at least in this case, following a primarily economic and technological agenda does not contradict what is desired by humanists.

\section{Works Cited}

Anderson, Chris (2007): The Long Tail - Der lange Schwanz. München: Hanser.

Barney, Jay B./Hesterly, William S. (2012): Strategic Management and Competitive Advantage: Concepts and Cases [int. edition]. Upper Saddle River: Pearson.

Bläsi, Christoph (2019): “Kl im Verlagswesen. Hilfreiche Werkzeuge mit Disruptionspotential und Herausforderung für Selbstverständnis und Verantwortung [Artificial Intelligence in Publishing. Helpful Tool with the Potential for Disruption and Challenge to SelfConception and Responsibility] ". In: Klimczak, Peter/Petersen, Christer/Schilling, Samuel (eds.): Maschinen der Kommunikation. Interdisziplinäre Perspektiven auf Technik und Gesellschaft im digitalen Zeitalter [Machines of Communication. Interdisciplinary Perspectives on Technology and Society in the Digital Age]. Heidelberg: Springer, pp. 167-187.

Bläsi, Christoph (2015): "Literary Studies, Business Studies - and Information Science? Yes, It's a Key Discipline for the Empowerment of Publishing Studies for the Digital Age". In: Pehar, Franjo/Schlögl, Christian/Wolff, Christian (eds.): Re:inventing Information Science in the Networked Society. Proceedings of the 14th International Symposium on Information Science (ISI 2015). Boizenburg: Hülsbusch, pp. 81-92.

Börsenverein des Deutschen Buchhandels (eds.) (2019): Buch und Buchhandel in Zahlen 2019. Frankfurt: Buchhändler-Vereinigung.

Hardt, Petra Christina (2015): Buying, Protecting and Selling Rights: wie man urheberrechtlich geschützte Texte erwirbt, sichert und verbreitet. Frankfurt am Main: Bramann.IPR License (2017): IPR, <https://iprlicense.com/> (last visit: 20/01/17).

Maxwell, John W. (2014): "Publishing Education in the 21st Century and the Role of the University". In: The Journal of Electronic Publishing, <http://dx.doi.org/10.3998/ 3336451.0017.205> (last visit: 20/01/17).

Miller, Mareike (2019): "Why Permissions Licensing is a Perfect Area for Automation". In: IPR License Blog. <https://iprlicense.blog/2019/03/11/why-permissions-licensingis-a-perfect-area-for-automation/> (last visit: 20/01/17).

Owen, Lynette (2014): Selling Rights. London: Routledge.

Qualifiction (no date given): Qualifiction, <https://www.qualifiction.info/> (last visit: 20/01/17).

Reason Street (2017): “Long Tail”. In: Business Model Library, <https://reasonstreet.co/busi ness-model-long-tail/> (last visit: 20/01/17).

Tappuni, Jane (2018): “Our rights process is broken. Can blockchain fix it?”. In: BookBrunch, <http://www.bookbrunch.co.uk/page/free-article/our-rights-process-is-broken-canblockchain-fix-it/> (last visit: 19/06/06). 
